\title{
Morse, Richard (Org. Beatriz Helena Domingues) Cidades e cultura política nas Américas
}

Ana Claudia Veiga de Castro*

Belo Horizonte: Ed. UFMG, 2017. 277p.

Mais conhecido no Brasil por ter publicado nos anos 1980 o livro O Espelho de Próspero (Morse, 1988), uma polêmica tese sobre as duas Américas, o historiador norte-americano Richard Morse também é o autor de uma série de ensaios sobre as cidades latino-americanas e o papel do pesquisador social. É um conjunto expressivo desses ensaios que vem agora a público no volume organizado pela historiadora Beatriz Domingues: Cidades e cultura política nas Américas. O livro reúne textos escritos por Morse entre 1954 e 1992, meio século de uma intensa produção intelectual enquanto era professor e pesquisador de algumas das principais universidades norte-americanas.

Morse iniciou seu percurso acadêmico nos anos 1940, e após graduar-se em História na Universidade de Princeton veio ao Brasil, em 1947, para realizar a pesquisa de campo de seu doutorado em Columbia, sob orientação do antropólogo Frank Tannenbaum. Interessado em compreender como uma pequena vila sem grande importância no sistema colonial português vinha se tornando a principal metrópole latino-americana, Morse passou mais de um ano em São Paulo, onde travou relações duradouras com Antonio Candido e seu grupo na Universidade de São Paulo, encantando-se pelo Modernismo e pela vibração daquela metrópole em formação. O resultado da tese foi o livro Formação Histórica de São Paulo: de comunidade à metrópole, publicado pela primeira vez nas comemorações do IV Centenário de São Paulo, com o título De comunidade à metrópole: a biografia de São Paulo, e republicado em 1970 na famosa coleção Corpo e Alma do Brasil, dirigida por Fernando Henrique Cardoso (Morse, 1954; Morse, 1970). A obra tornou-se um clássico da história urbana de São Paulo, podendo também ser lida como um esquema de interpretação sobre a forma de desenvolvimento da cidade capitalista no mundo ibero-americano e, talvez, como vislumbre de uma outra modernidade. Pode-se dizer

* Universidade de São Paulo, Faculdade de Arquitetura e Urbanismo. São Paulo, SP, Brasil. anacvcastro@ usp.br 
que essa tese (e sua experiência em São Paulo) abriu os olhos de Richard Morse para o problema da urbanização latino-americana e para a cultura urbana em geral definindo a importância dessa perspectiva analítica para seu entendimento do mundo social -, resultando em textos, intervenções e organização de livros.

Parte dessa produção é agora publicada: nunca traduzidos e de difícil acesso ao pesquisador brasileiro, estes artigos podem ser lidos de maneira complementar aos trabalhos de maior fôlego do pesquisador, desenhando o percurso de seu pensamento ao longo dos anos e revelando a erudição e a perspicácia de um intelectual que não se contentava com visadas ortodoxas, buscando escapar da ideia de modelos e desvios, valendo-se da compreensão de sistemas de pensamentos.

O primeiro desses ensaios, "Rumo a uma teoria de governo para a América Espanhola”, publicado ainda em 1954 no Journal of History of Ideas, recupera a presença hispânica na América e discute as heranças medieval e renascentista na formação do novo continente, sobretudo nas suas cidades, indicando a impossibilidade de se lidar com as nações de origem ibérica na América seguindo a régua da América anglo-saxã, formada desde uma origem diversa não apenas espacial, mas também temporal. O ensaio anuncia um tema que Morse revisita ao longo da carreira e que encontra sua forma final no já citado Espelho de Próspero.

Em seguida, "São Paulo desde a independência: uma interpretação cultural", publicado no mesmo ano, desta vez na Hispanic American Historic Review - a mais importante publicação dos estudos históricos latino-americanos nos Estados Unidos -, apresenta uma espécie de síntese de sua tese sobre São Paulo e introduz o leitor à compreensão das cidades a partir de uma mirada cultural. Num momento em que os pesquisadores se debruçavam sobre os problemas advindos da intensa urbanização das cidades latino-americanas - que sem o necessário lastro na industrialização resultava num conjunto expressivo da população empregado nas margens do sistema, abrigado em imensas áreas periféricas sem infraestrutura urbana adequada -, Morse indicava a potência da cultura para o conhecimento dessas cidades, e a própria importância das cidades, com suas instituições culturais, para que se pudesse tratar "de forma eficaz [até mesmo] os insistentes problemas agrários da América Latina” (p.106). Esta última afirmação do ensaio evidencia como, para Morse, o trabalho intelectual não era desprovido de intenções, comprometendo-se, ao fazer história, a discutir o desenvolvimento do subcontinente, em diálogo com pesquisadores como Robert Redfield e Oscar Lewis, que se dedicavam naqueles anos à compreensão das especificidades do fenômeno urbano latino-americano.

Dois outros ensaios publicados na mesma Hispanic American Historic Review, "Algumas características da história urbana da América Latina" (de 1962) e "Prolegômenos para a história urbana da América Latina” (de 1972), foram escritos quando Morse era professor de História da América Latina, primeiro na 
Universidade do Estado de Nova York e em seguida em Yale, onde se envolveu em diversas ações para a consolidação da história urbana como uma disciplina, participando de congressos, coordenando simpósios, organizando volumes - entre os quais, alguns trabalhos com o argentino Jorge Enrique Hardoy que geraram aportes decisivos ao campo.

No primeiro, Morse retoma ideias trabalhadas em um texto publicado em 1957 na revista Estudios Americanos, "La ciudad artificial", escrito como comentário da mesa "Expansão urbana na América Latina durante o século 19”, em uma reunião da American Historical Association no qual anunciara a cidade na América Latina como algo "artificial” ao ser lida à luz da história urbana europeia. Já ali Morse defendia a necessidade de uma história cultural urbana como a única forma de não ver a América Latina como desvio da "civilização ocidental". Mas se havia especificidades em relação à urbanização europeia e também à da América anglo-saxã, havia um paradoxo que valia tanto para a América do Norte quanto para a do Sul: "que a cidade, notória na Europa por seu raio comercial e por sua atividade manufatureira, serviu, no Novo Mundo, como ponto de partida para o contato com o solo, em territórios onde nenhuma rota de comércio interno havia sido definida e onde a manufatura era restringida pelas políticas do mercantilismo" (p.135). Isso teria feito do espaço, e não do tempo, "o principal fator da experiência americana", tornando a cidade na América uma força centrípeta. Com isso, Morse anuncia a urbanização latino-americana como chave para a compreensão dos sentidos da América. E que, se quisermos lembrar, seria o mote de Ângel Rama em seu fundamental La ciudad letrada (1984): o reconhecimento do papel das cidades (e das letras) na constituição da América Latina (Rama, 1986).

No segundo ensaio, discutindo com uma bibliografia clássica que ia de Henri Pirènne a Max Weber, Morse uma vez mais trabalha a especificidade da urbanização latino-americana desde sua origem, recuando desta vez aos primórdios da urbanização na Europa, a polis grega, de modo a definir a gênese mesma da cidade enquanto instituição política e social, para compreender o papel das cidades na constituição dos Estados nacionais modernos europeus. Buscando definir caminhos para construir uma história urbana latino-americana, não teve receio em enfrentar outros pesquisadores, recuperando e debatendo com suas teses de modo a indicar os "furos", as incongruências, e mais que tudo, um eurocentrismo de fundo que impedia um olhar menos formatado para a América Latina. Em tempos de Cepal e de outros órgãos que enfrentavam questões latino-americanas para a construção de sua autonomia, Morse se colocava como um interlocutor importante àqueles que queriam formular um pensamento próprio do e para o subcontinente.

Completando o volume, a resenha de um livro publicado nos anos 1960, o texto "O antropólogo como consultor político", e por último o ensaio "Cidades como 
pessoas", publicado na obra Rethinking the Latin American City, organizada com Hardoy já em 1992, espécie de balanço de seu pensamento sobre o papel das cidades e as diferenças e as aproximações entre os modelos urbanos do norte e do sul.

Vale destacar que os textos de Morse são precedidos por um ensaio de fôlego da sua organizadora, Beatriz Domingues, que conheceu o pesquisador em 1991. Sua apresentação introduz o leitor aos temas de eleição de Morse e propõe uma sistematização de sua trajetória a partir de um "pressentimento metodológico", como ela diz, adaptando as etapas de um trabalho do pedagogo Alfred North Whitehead para organizar sua obra em três fases. A historiadora já havia nos oferecido uma série de textos críticos sobre Richard Morse no livro organizado com Peter Blasenheim, O Código Morse: ensaios sobre Richard Morse (2010), também editado pela UFMG (Domingues; Blasenheim, 2010). Aqui, dá início ao trabalho de publicização dos escritos do autor e já anuncia sua continuação em um segundo volume. As traduções bem cuidadas, feitas pela jornalista Maria Bitarello (filha de Beatriz e que conheceu Morse na infância), garantem uma leitura fluida e agradável. O livro conta também com uma apresentação do jornalista Matthew Shirts (ex-aluno de Morse em Stanford) e um posfácio da historiadora Helena Bomeny, autora de uma entrevista com o historiador no final dos anos 1980 (Bomeny, 1989). A edição, que traz ao final a cronologia das obras de Richard Morse, é portanto muito bem-vinda, pois oferece um importante material para pensarmos nosso lugar no mundo, sobretudo hoje, neste momento crucial de definição de caminhos. Vale a pena ler, conhecer e refletir.

\section{REFERÊNCIAS}

BOMENY, Helena. Uma Entrevista com Richard Morse. Estudos Históricos, Rio de Janeiro: Ed. FGV, v.2, n.3, p.77-93, 1989.

DOMINGUES, Beatriz; BLASENHEIM, Peter (Org.) Código Morse: ensaios em homenagem a Richard Morse. Belo Horizonte: Ed. UFMG, 2010.

MORSE, Richard. De comunidade a metrópole: biografia de São Paulo. Trad. Maria Aparecida Madeira Kerberg. São Paulo: Comissão do IV Centenário, 1954.

. O Espelho de Próspero: cultura e ideias nas Américas [1982]. Trad. Paulo Neves.

São Paulo: Companhia das Letras, 1988.

Formação histórica de São Paulo: de comunidade a metrópole. Trad. complemen-

tares Antonio Candido. São Paulo: Difel, 1970.

RAMA, Ángel. A cidade das letras [1984]. Trad. Emir Sader. São Paulo: Brasiliense, 1986.

Resenha recebida em 4 de agosto de 2017.

Aprovada em 2 de setembro de 2017. 